\title{
Integration of Globalization and Localization of TNCs and Corresponding Strategy of China
}

\author{
Qingbo Huang \\ Transportation Management School, Dalian Maritime University, Dalian, China \\ hqb4950@126.com
}

Keywords: Globalization; Integration; Localization; TNCs.

\begin{abstract}
Integration of globalization and localization has become inevitable trend of management activity of TNCs (Transactional Corporations). The paper begins with theory, which accounts for integration of globalization and localization, furthermore, it analyses the relationship between the integration and fostering of competitive advantage. Moreover, from practice, it cites case of Motorola and Haier as to present corresponding strategy of China.
\end{abstract}

\section{Introduction}

With approaching of era of globalization, TNCs adopt global strategy to attain longstanding benefit, stable competitive advantage and maximize their global efficiency. Meanwhile, management activity of TNCs has been more emphasized on integration with local environment, say localization. Integration of globalization and localization has become the prominent form of TNCs.

\section{Theory accounting for Integration of Globalization and Localization}

Globalization is defined as increase of exchange of transnational commodity and service trade, expanding international capital flow, worldwide prevalence of technology, as to intensify the mutual dependence of global economy entities. Through FDI (Foreign Direct Investment) and joint venture, TNCs have become entity of globalization and fulfil their task globally. Globalization of TNCs will result in worldwide uniform standard in products, scale of economy and quality, which are more to be acceptable to the world community so as to prevail. Localization materializes in sale, production, capital, management and R\&D etc, so far it' $s$ also the reflection of local culture because national culture lacks impact friction and challenge. As for the active role played by TNCs, in production management and global marketing process, localization lies in developing strategy such as catering to local custom and religious belief so to facilitate TNCs to become a part of local nation.

Globalization and localization is dialetic. Whether globalization or localization is to describe how an enterprise adjusts to local culture when entering into different societies and markets: localization of an enterprise is an imperative part of globalization. And different definitions aim at two sides of a coin. On one side, globalization can't exist without localization, in itself, localization is the key of a TNC's global strategy, and intensified localization will accelerate development of globalization. On the other side, factor of globalization will inevitably affect local value and culture. As illustrated by many theories, management activity of TNCs must realize integration of globalization and localization.

In 1977, professor J.H.Dunning, of represented, "Trade, Economic activity and TNCs: analysis on the Eclectic Theory of International Production [1]", in this paper he holds the view that when a TNC adopts FDI choice, it must not only considerate location advantage but also internal monopolization and internalization advantage. Monopolization and internalization advantage are owned by an enterprise, and monopolization advantage is an imperative condition in FDI, while internalization depends on global net constructed by TNCs, as to reflect the essence of globalization. As for location advantage, it's factor of local nation such as geographical distribution of production factor and market, 
production and transportation cost, investment and cultural environment etc. If only three advantages are together, FDI activity can be feasible.

Professor Kiyoshi Kojima pointed out that FDI should begin with comparative disadvantageous industry, which lost or is losing developing space, meanwhile, FDI should be in accordance with local industrial development. Therefore, Kiyoshi Kojima figured out: other nations are in an advantageous or potential advantageous location, and FDI should begin with these kinds of industries. As what the theoretics explained, when adopting FDI a nation should consider enterprises both at home and abroad, as to research local industrial development. Similarly, process of global industry transmission should integrate with localization.

Economist Sanjaya Lall drew his attention to localization of technology. He analysed from micro-economy which is mainly emphasized TNCs of developing countries, so that he proved the possibility of less-developed countries engaging in international production and management with comparative advantage, in other words, they update and innovate introduced technology to turn it into their own competitiveness. This innovation will be affected by local supply and demand, and all could be strengthened by local or lingual contact. In conclusion, if globalization could be integrated with localization, technology will be further innovated.

\section{Integration of Globalization and Localization \& Competitive Advantage}

Michael E. Porter, professor of American Harvard University, pointed out, "Competitive advantage is a process to attain excessive benefit by surpassing competitors. Basically, competitive advantage is the value created by enterprises, equally, it's the lower price given the coequal conditions or equalization to compensate excessive price"[2]. Competitive advantages possessed by a corporation are cost advantage and diversification advantage, which manifest integration of globalization and localization.

Assumption of Cost Advantage: Globalization. National resources exist differently, and management activities of corporations vary at $\mathrm{R} \& \mathrm{D}$, production, marketing etc., as well as production factors. Thereby corporation could arrange production activity in a global scope through transnational management, in other words, it transfers the activity, which requires maximum production factor to a nation with minimum price.

Globalization avails to realize economy of scope, that is to decrease unit cost through macro production, as a result, cost advantage will be achieved. Generally, components production bears maximum production scope, assembly activity rants second. When a corporation is provided with global advantage of scope, it can farthest utilize global resources and reduce cost. Accordingly, global corporation possess of lower cost.

Besides, economy of scope acquired by standard production is accompanied by flexible management and decreased adjustment to external changes, especially when national demand varies, economy of scope will decline. Thus, a corporation should considerate diversification to obtain competitive advantage.

Assumption of Diversification: Localization. Diversification and variability characterize Tran national management environment. In some market, national diversification varies a lot. In different nations, customer reaction and taste, circulation system, intervention adopted by administration aiming at regulating commodity and market competitive activity will actualise direct influence on promotion strategy and marketing method. According to characteristics of local market demand, a corporation can design and produce commodity, so as to enhance appreciated value.

Meanwhile, local government will support localization, which further veils diversification advantage. If export of production factor of a TNC conforms to development strategy of a nation, or localization strategy caters for demand of local nation, the TNC can expand local market, as well as protection and support from local administration.

Judging from two advantage sources, localization is the source of both diversification and cost advantage. For example, localization can avoid trade barriers and facilitate them to open up new 
market. All mentioned could save cost. Similarly, globalization will assist attaining diversification. Consequently, only globalization can bridge the gap of overflow and realize diversification. Further, integration of globalization and localization will foster competitive advantage.

Integration of Globalization and Localization_-Fostering Competitive Advantage. Ambiguity of Nationality of TNCs. Economic scale, business scope and influence of TNCs has exceeded national and geographical boundary. They are alliance worldwide instead of geographical and national centre, and the core of it is not national benefit but profit of a corporation. Diversification of owner's equity characterizes ambiguity of nationality of TNCs as mutual equity, as to strategic alliance.

Ambiguity of Nationality of Product. Complete localization is impossible for a TNC characterized by de-economic and unpractical result. Globalization breaks nationality limit of product and results in cross-national production, further formalize global entity within which all nations mutually depend on and compensate. In relative countries, TNCs organize specialized production, herewith, internal trade links production and procedure. All domestic production procedure constitutes global production, and national component catering for "local taste"turns into "international integrated product" [3]. "international integrated product" is aggregation of global advanced technology and best allocation of resources, technology and managerial factor.

Integration of Globalization and Localization of R\&D. With further development of economic globalization, R\&D investment from TNCs increases annually, involving some newly industrial nations and developing countries. Transnational merger provides more opportunity for founding of overseas R\&D. Wherefore, flexibility of transnational R\&D enhances. With premise of global R\&D cooperation and R\&D net, researchers can keep in touch with research base momentarily, so as to attain knowledge. Thus R\&D institution is developing at a trend of minitype and decentralization. Thereby, local R\&D resources have invited more attention.

\section{Case Analysis on Integration of Globalization and Localization}

Moto (Motorola Inc.) is an American corporation engaging in local management in China. Haier Co. is a Chinese company in line with local business in America. Both companies are typical in integration of globalization and localization.

Globalization of Motorola Inc. and Localization in China. With global purchasing, sale and $\mathrm{R} \& \mathrm{D}$, Moto also stresses localization in China. Its future development strategy is 'to construct unbreakable strategic fellowship with China' and to aim at becoming a completely local Chinese company. In localization of human resource, Moto insists on 'best staff is from local company', hence, it requires localization from senior management to common employees. In localization of brand name, Moto adopt cultural penetration of brand name, meanwhile it engages in welfare actively. In localization of supply chain, Moto establishes long-term mutual-benefit relationship with suppliers, and assists them to draft updating plan in production technology and management.

Globalization of Haier and Localization in America. With the global strategy, Haier emphasizes Localization in American market. In localization in human resource, much as production centre in U.S is a sole-owned enterprise, central managers and more than 200 employees are Americans except for several Chinese. In localization in production, Haier production centre is located in U.S, which overcomes the difficulty such as tariff barriers and non-tariff barriers, meanwhile, it obtains advantage in human resource, capital and technology. In localization of R\&D, 'Haier Design Centre' is located in Los Angeles, mainly responsible for exploring new type products, which meets different demand from customers and reacts duly. In localization in brand name, Haier adopts cultural penetration targeting at local community, which wins identification and avoid of exclusivism from local consumers. 'Haier Production Centre' entitles all product made by Haier with label as 'MADE IN USA', which endows Haier with local products. 
Comparative Analysis on Motorola Inc. and Haier Co. As a typical example, Haier bears hope of internationalisation of China Corporation. Whereas we compare Haier with Moto, it's clear to see the gap between two companies.

Haier lays particular stress on localization of man instead of human resource. Much as Haier established its own university, Haier University is located in China, which can't cater for American culture, market and consumers.

Investment in localization of Haier is much lower than Moto, which is 2.4 hundred million RMB, while figure of Moto reaches 28 billion RMB.

Haier has only one production centre in U.S which may result in increased transportation cost, decreased adjustment to customer reaction, ultimately, it will restrict development of the company.

Moto leads customer demand. It fractionalises customer demand instead of a standard to measure mobile phone's function; especially they explore potential customer demand and make up-to-date products. Nowadays, most TNCs promote standard instead of products, which brings sustained benefits.

\section{Inspiration for China Brought by Integration of Globalization and Localization}

Organizing Global Productions and Decreasing Production Cost. With impetus of globalization, nationality of corporations and products plays a less important role. According to recent statistic data, top TNCs enjoy high degree of Tran nationalization [4]. Our per average resource owning rate is comparatively low, however with globalization, our corporations can utilize raw materials and energy resources worldwide so as to realize co-sharing resource globally. From macro economy, we can adopt resource-oriented FDI strategy; among these industries China will lose its comparative advantage. By joining in global production, we can sustain economy of scale and cut down cost.

Moreover, Chinese enterprises can make best use of financial tools to decrease cost on financing. Contrastively, finance in western countries developed fast with large capital and smooth financing channels. Only if Chinese enterprises enjoy reliable credit and P-E rating(Price to Earning Rating), can they easily obtain loan and expand operation scale.

Promoting Relevance between Enterprise and TNCs. Establishing Relevance. As characteristics of current industrial organization, globalization and information result in rapid changes in production factor, resources and distribution, and accelerate economic centralization in special zone where exist amounts of terminal products and corporation engaging in service, including providers, logistics and other organization in line with service, financing and technology support. If relevance between enterprise and TNCs has come into existence, this economic zone can attract TNCs to invest and FDI so as to form production base. Through relevance, knowledge, technology and advanced management experience can transfer to local corporations, and the latter can increase competitive capacity with cooperation with TNCs. If not, foreign TNCs will step into isolated economy. Among three methods, back-relevance, which means relevance between foreign subsidiary of TNCs and domestic corporations, plays a more important role. So that local corporations can decrease cost by utilization of lower price, in addition, outsourcing can upgrade specialization and flexibility by adjusting to local environment.

Advantage of Centralization. Through centralization, TNCs can be promoted and less detracted [5]. In neighbourhood of centralization, credit system and longstanding mutual trust relationships can be feasible. Nowadays in Chinese the Yangtse Delta and Zhu River Delta, economy of centralization has existed [6]. Advantage of centralization and location advantage of TNCs is a procedure of mutual promotion. Preliminary condition for centralization is geographical boundary and relevance in industry [7]. Nevertheless, first TNCs in these zones are attracted by non-centralized factors, which are geographical advantage and non-material advantage (including market system, preference of current policy); When an economic zone is provided with preliminary factor of centralization, geographical is weakened while with increasing of centralization advantage [8]. Herein, what attracts 
TNCs is centralization advantage instead of ordinary location advantage [9]. Therefore, with time going, centralization advantage will accelerate attracting more FDI.

Increasing Standard of R\&D and Fostering Competitive Advantage. Intensifying International Cooperation on $R \& D$. Globalization accelerates expansion of $R \& D$, while internationalisation makes technology innovation with more transparency and distribution, with which, China becomes globally important manufacturing base. Till now, investment brought by TNCs diverts from machining and manufacturing fields to knowledge fields such as training , distribution and R\&D etc. [10] Distinguished foreign TNCs open up China R\&D market, such as IBM, Intel, Microsoft, GE Auto, Erisson, Panasonic, Nokia and Unilever etc, they established R\&D branch in Beijing and Shanghai, and cooperated with Qinghua University, Peking University with setting up lab, $R \& D$ centre and training centre etc, which provides China with rare opportunity in international cooperation.

Expanding Technology Spillover Effect. To attract technology innovation human resource and encourage overseas talented to world in China branch of TNCs, we can apply their advanced methods, mind and culture into practice, and encourage cooperation with local university, R\&D institution or corporation, which promotes technology spillover effect. Utilization of flexibility of human resource will promote local technology innovation, for example, when Japan and Korea experienced economic developing period with high speed, some of internal senior managers are from TNCs branch. In addition, they apply advanced technology and managerial experience into internal corporation as to increase local technology innovation capacity.

\section{Acknowledgements}

The paper is subsidized by Liaoning province social science fund project (L14AJY001, L15BJL015) and Basic scientific research fund project of central university (3132016037)

\section{References}

[1] Trade, Location of Economic Activities, and the MNE: A Search for and Eclectic Approach, in B. Ohlin ed, International Allocation of Economic Activity, Holms\&Meier, 1977.

[2] Michael E. Porter: Competitive Advantage of Nations, The Free Press, 1990, pp1-2.

[3] Lin Kang, TNCs and Transnational Management,(in Chinese), the University of International Economics and Trade Press, July 2000, pp42-43.

[4] UNCTAD, Referred three average ratio (Foreign assets/ Gross assets, Foreign sales/gross sales, Foreign employee/gross employee), translated by Xian Guoming, 2000 World Investment Report, (in Chinese), China Finance Economics Press, July 2001, pp150-151.

[5] UNCTAD, translated by Xian Guoming, 2000 World Investment Report, (in Chinese), China Finance Economics Press, July 2001, pp150-151.

[6] Arslan, A. and Larimo, J. Ownership Strategy of Multinational Enterprises and the Impacts of Regulative and Normative Institutional Distance: Evidence from Finnish Foreign Direct Investments in Central and Eastern Europe [J]. Journal of East-West Business, 2010, 16(3): 179-200.

[7] Kostova, T. and Zaheer, S. Organizational Legitimacy under Conditions of Complexity: The Case of the Multinational Enterprise [J]. Academy of Management Review, 1999, 24(1): 64-81.

[8] Phillips, N. , Tracey, P. and Karra, N. Rethinking Institutional Distance: Strengthening the Tie between New Institutional Theory and International Management [J]. Strategic Organization, 2009, 7(3): 339-48.

[9] Ren Shenggang, Centralization and Effect on Competitive Advantage of TNCs, (in Chinese), 
Research on Trade, Sep, 2004, pp78-79.

[10] Hofstede, G. Culture's Consequences : International Differences in Work-related Values [M].Beverly Hills: Sage, 1980. 